\title{
NOVAS TECNOLOGIAS E A RECONFIGURAÇÃO DO PÚBLICO E PRIVADO NO ESPAÇO DA CASA
}

\author{
NEW TECHNOLOGIES AND THE RECONFIGURATION OF THE \\ PRIVATE AND PUBLIC WITHIN SPACES IN THE HOUSE \\ NUEVAS TECNOLOGÍAS Y LA REORDENACIÓN DE LOS ESPACIOS \\ PÚBLICOS Y PRIVADOS EN LA CASA
}

Tania Montoro ${ }^{1}$

Pós Doutora em Comunicação Audiovisual Universidade Federal do Rio de Janeiro (UFRJ).

taniasmontoro@gmail.com

Denise Cavalcante ${ }^{2}$

Professora da Faculdade de Comunicação Universidade de Brasília (UNB). tatogabo@gmail.com

\begin{abstract}
Resumo
Em que medida a chegada de novas tecnologias da comunicação alterou a configuração dos espaços internos de uma casa? Como definir a casa como espaço privado, se em seu interior há o domínio do espaço público? A partir da existência de uma contraposição entre espaço público e privado, busca-se analisar as transformações sofridas no espaço da casa. Este artigo pretende traçar linhas entre público e privado articulando a nova configuração do espaço doméstico e sua relação com os meios de comunicação na sociedade contemporânea.
\end{abstract}

Palavras-Chave: novas tecnologias - comunicação - espaço doméstico 


\begin{abstract}
Is the advent of new communication technologies changing the configuration of the internal spaces of a house? How to set a home as a private space, if in its interior there is a domain of public space? Starting from the existence of an opposition between public and private space, seeks analysis of transformations in the space within a home. This article aims to draw the line between public and private, articulating the new configuration of domestic space and its relationship with the media in contemporary society.
\end{abstract}

Key Words: new technology - communication - domestic space

\title{
Resumen
}

¿En qué medida la aparición de nuevas tecnologías de comunicación ha cambiado la configuración de los espacios interiores de una casa? Cómo configurar la casa como espacio privado, ya que en su interior ha el dominio del espacio público? Desde la existencia de una oposición entre espacio público y privado, tiene como objetivo analizar las transformaciones en el hogar. Este artículo pretende dibujar líneas entre lo público y privado, articulando la nueva configuración del espacio doméstico y su relación con los medios de comunicación en la sociedad contemporánea.

Palabras-Clave: nuevas tecnologías - comunicación - espacio doméstico

\section{Espaço público e espaço privado}

Se vamos investigar espaço público e espaço privado a partir do estudo da casa, partimos de imediato da idéia de espaços dinâmicos, concebidos a partir de contextos próprios, variáveis segundo a realidade a qual pertencem e integrados em um sistema de relações e valores de uma sociedade. Deste modo, cada sociedade pode ser entendida, inicialmente, a partir da relação entre esses espaços, possibilitando conceber uma significação entre o sujeito e o lugar a qual pertence.

A partir da proposição de Jürgen Habermas (1984), nos permitimos analisar os conceitos de espaço público e privado dentro de um escopo da existência de uma contraposição. Assim, o primeiro se apresenta como um espaço acessível a qualquer um (o que não significa que todos teriam acesso a ele), impessoal, aberto à circulação pública e o segundo, como todo espaço que 
não é público, particular a cada indivíduo, que fica oculto dos olhares estranhos. Enquanto o espaço público estaria relacionado à vida em sociedade, pertencente ao Estado e à esfera do governo, o espaço privado ficaria restrito à vida íntima; para Habermas, a esfera privada estaria ligada a casa e se confundiria com a vida em família.

No livro Pela Mão de Alice, Boaventura Santos (2000, p.125) apresenta o espaço doméstico como um dos quatro espaços estruturais das sociedades capitalistas, compostos individualmente "por uma prática social, uma forma institucional privilegiada, um mecanismo de poder, uma forma de direito e um modo de racionalidade". Além do espaço da família, o autor reconhece o espaço da produção constituído pelas relações de trabalho, e da cidadania formado pelas relações sociais da esfera pública entre cidadãos e o Estado, e o espaço da mundialidade que constitui as relações econômicas internacionais. Nesta proposição configura-se a divisão do espaço público em outros três setores, sendo que o espaço do trabalho pode, momentaneamente, se identificar ao espaço doméstico. De qualquer forma, não é possível separar nitidamente espaço público e privado, pois os dois fazem parte de uma mesma esfera contínua que possibilita diferenciá-los e aproximá-los simultaneamente (SENNETT, 1988).

Público e privado fazem parte de um mesmo universo que permite relações diversas numa construção permanente. Para Habermas (1984), o setor privado também abrange a esfera pública, pois é em si uma esfera pública de pessoas privadas. A esfera pública fica entendida como "a esfera das pessoas privadas reunidas em um público". Na concepção de espaço público de Hannah Arendt (1993), se projetam nitidamente elementos do espaço privado. Para ela, as atividades que servem para a conservação da vida privada podem estabelecer as características do espaço público. Segundo Richard Sennett (1988), a família constitui uma barreira de proteção contra a ordem pública, enquanto a experiência pública está diretamente ligada à formação da personalidade individual.

Não existe uma vida privada de limites definidos para sempre, e sim um recorte variável da atividade humana entre a esfera privada e a esfera pública. A vida privada só tem sentido em relação à vida pública, e sua história é, em primeiro lugar, a história de sua definição (PROST; VINCENT, 2009, p.14).

Todos esses exemplos servem para esclarecer o quanto é difícil pensar em um espaço privado sem relacioná-lo a um espaço público ao qual está interligado. Assim, pretendemos analisar o espaço da casa sem limitá-lo a uma mera distribuição física, mas a partir de tensões 
possíveis entre sua esfera privada e os diversos espaços públicos que o permeiam, repousando na imagem de que "a linha entre a esfera privada e a esfera pública passa pelo meio da casa" (HABERMAS, 1984, p.62).

\subsection{O público e o privado na casa}

A casa sempre esteve associada à noção de abrigo, tomada como sinônimo de espaço privado onde o indivíduo encontra acolhimento e proteção do mundo exterior. A casa "é o nosso primeiro universo. [...] A vida começa bem, começa fechada, protegida, agasalhada no regaço da casa” (BACHELARD, 1993, p.24). É a partir da casa que o sujeito se amplia para outros espaços. "Antes de ser jogado no mundo [...] o homem é colocado no berço da casa" (idem, p.26).

A presença do homem no espaço é a essência da casa. A casa só existe enquanto espaço real quando habitada; sem o sujeito presente, a casa é apenas uma área geométrica, um espaço vazio, ausente. Nela, o homem cria barreiras e limites, dividindo o interior e o exterior. Gaston Bachelard (idem, p.219) separa o dentro e o fora a partir dos espaços da casa: "o interior e o exterior não recebem do mesmo modo os qualificativos, esses qualificativos que são a medida da nossa adesão às coisas. Não se pode viver da mesma maneira os qualificativos ligados ao interior e ao exterior".

Do mesmo modo, o público e o privado também se revelam por meio da utilização dos espaços da casa. A oposição entre o espaço público e o espaço privado se expõe na apropriação dos cômodos de uma casa. O sujeito condiciona suas atividades a determinados espaços, provocando formas e articulações que se enquadrem com suas necessidades. Dentro dos domicílios é possível buscar fragmentos de uma vida condicionada à cultura de seus usuários e a valores particulares.

A casa permite abrigar atividades bem distintas como cozinhar, trabalhar e se relacionar intimamente. As esferas públicas e privadas estruturadas no espaço da sociedade são transportadas para dentro da casa. Assim como os limites entre público e privado passaram por constantes mudanças na sociedade, grandes transformações ocorreram no espaço da casa, sendo o mais visível referente ao trabalho. Na estrutura básica da esfera pública apresentada por Habermas (1984), o setor privado abrange a esfera privada que compreeende a sociedade civil, 
isto é o setor de troca de mercadorias e o trabalho social, enquanto na esfera íntima, se encontra a família.

A casa reproduz em seus espaços, diferenciações estabelecidas na sociedade. No Brasil, primeiramente, o trabalho representava uma categoria social integrada ao espaço privado da casa; os negócios apareciam como um prolongamento da vida privada. A indústria caseira e a agricultura familiar ocupavam todos os moradores envolvidos na rotina de uma série de atividades, tornando as moradias auto-suficientes. Marido e mulher dividiam sob o mesmo teto as funções de sustento, produzindo o necessário para sua sobrevivência. Dentro da casa, fazia-se desde vestimentas e utensílios até a produção alimentícia necessária para o dia-a-dia (NOVAIS et al., 1997). O espaço doméstico estava demarcado por um cotidiano pleno, compreendendo a vida íntima da família assim como seus ofícios.

Durante o século XX, respondendo a reinvindicações econômicas de aumento de renda e de maior regularidade na vida privada, entre outras, o trabalho deixa a esfera privada e ingressa na esfera pública. Enquanto o trabalho se estabelece em lugares impessoais regidos por normas públicas, a casa se constitui como espaço de uma vida dedicada à família, acentuando o contraste entre esfera pública e esfera privada.

A maior diferenciação entre o público e o privado no conjunto da sociedade modifica tanto a vida pública quanto a vida privada. Ambas já não se desenrolam da mesma maneira, nem segundo as mesmas regras. Enquanto suas fronteiras se deslocam e se definem com maior precisão, simultaneamente sua substância se transforma (PROST; VINCENT, 2009, p.17).

A divisão espacial da casa em cômodos se apresenta como uma necessidade social do indivíduo. Em sua forma arquitetônica, o espaço interior da casa se transforma, deixando transparecer novas necessidades. Cavalcanti e Guimaraens (1984) apontam para uma tendência em privatizar os espaços da casa e separá-los em setores, associada à valorização da família e à “ânsia da individualização". Os espaços da moradia são organizados entre público e privado, compreendendo os setores íntimo, social e de serviço.

A sala de visita, a cozinha e o quarto de dormir se encontram sob o mesmo teto, mas não pertencem à mesma categoria de espaços. Em geral, dentro do espaço doméstico, os dois primeiros pertencem ao domínio público, voltado aos empregados e aos visitantes; e no quarto, o indivíduo tenta salvaguardar sua privacidade. Do mesmo modo que o mundo do trabalho volta-se cada vez mais para a esfera pública, a família se torna cada vez mais privada. Habermas (1984, 
p.43) enfatiza que a casa, como a esfera da pequena-família, "é o local em que historicamente se origina a privacidade, no sentido moderno de uma interioridade livre e satisfeita".

\subsection{Contemporaneidade no espaço da casa}

O sentido de público e privado para aqueles que moram a quilômetros de distância uns dos outros em territórios pouco povoados assume conotações bem distintas diante da concepção dos espaços das grandes cidades. A cidade e suas articulações espaciais configuram um deslocamento da noção de espaço público e privado.

[...] novos espaços privados, semi-privados ou semi-públicos parecem haver assumido a função de abrigo da vida coletiva urbana. Abertos, em tese, de maneira irrestrita ao público, esses espaços, localizados no interior de áreas comerciais (shopping centers, casa de recepções) ou mesmo residenciais (condomínios horizontais ou verticais) são atualmente o palco de grandes eventos profissionais e familiares (FERREIRA; MARQUES, 2000).

Dentro da casa, a apropriação dos espaços acompanha essas transformações. A sala de jantar, antes espaço de convívio familiar é esquecida diante da correria diária em que poucos ainda têm tempo para refeições em casa; a sala de visita, anteriormente o espaço dedicado a amigos e familiares, é substituída por espaços da nova sociabilidade, remetida a ambientes privados em lugares públicos. O que ocorre é um esvaziamento das áreas sociais dentro das moradias que, associado a aspectos econômicos, provocam uma diminuição na dimensão destes espaços.

As transformações causadas pela modernidade fizeram com que a casa se fechasse em torno do círculo familiar. Grades nas janelas e altos muros circundam as residências dificultando ainda mais as relações sociais dentro do espaço doméstico. Mais do que nunca, a casa representa proteção contra os perigos do mundo contemporâneo. A urbanização das grandes cidades trouxe perturbações capazes de invadir a privacidade tranqüila dos moradores. A segurança é avaliada numa proporção direta à distância em que o indivíduo se encontra de sua casa: quanto mais próximo a sua casa, mais seguro ele se sente.

Assim como os novos imóveis residenciais apontam redução nos espaços de convivência, o aumento da dimensão espacial dos quartos indica novos comportamentos que privilegiam a introspecção do indivíduo. Habermas (1984, p.61) assinala que "o isolamento do membro da 
família, mesmo no interior da casa, passa a ser considerado como algo positivo", ressaltando que a casa se torna "mais habitável para o indivíduo, porém mais estreita e pobre para a família". Antes os quartos eram apenas chamados de quartos de dormir; hoje, acoplados a uma saleta, um closet, um banheiro e um pequeno escritório, são mini-residências independentes que permitem ao morador uma auto-suficiência e um "individualismo" espantoso. A esfera da privacidade deixa a família para se reduzir ao indivíduo.

\section{As novas tecnologias e o espaço da casa}

O espaço da casa se reestrutura novamente diante da presença dos novos meios de comunicação. Mais do que construir mini-residências independentes numa composição de closet, escritório e saleta, a casa passa a ser composta por mini-unidades constituídas de equipamentos pessoais como celular, microcomputador, internet, home teather, etc.

A chegada de novas tecnologias "re-estrutura" as barreiras existentes entre espaços públicos e privados. Anthony Giddens (1991) afirma que para entender as implicações da modernidade diante das mudanças do espaço da casa, é preciso ressaltar alguns aspectos do espaço no mundo pré-moderno.

As dimensões espaciais da vida social são, para a maioria da população, e para quase todos os efeitos, dominadas pela "presença" - por atividades localizadas. $\mathrm{O}$ advento da modernidade arranca crescentemente o espaço do tempo fomentando relações entre outros "ausentes", localmente distantes de qualquer situação dada ou interação face a face (GIDDENS, 1991, p.27).

A era pós-moderna fez mais do que esvaziar os espaços sociais da casa, ela conseguiu banir qualquer presença real dos espaços em geral. Até agora, as trocas sociais dependiam de uma proximidade física para acontecerem. O avanço tecnológico permitiu um novo tipo de sociabilidade, uma relação convivial entre pessoas ausentes, sem a necessidade de um contato direto entre elas. E para que um intercâmbio aconteça nesta "ausência", é preciso necessariamente a "presença" de um aparelho ou máquina que possibilite esse encontro.

As novas referências de espaço conduzem as relações sociais a outros locais de interação. As linhas que separam o espaço público do espaço privado se dissolvem porque a própria noção de espaço é dissolvida. Ter uma televisão ou um computador conectado com lugares do mundo inteiro, dentro de um espaço íntimo e menor, que é a casa, corresponde a compactar este mundo 
dentro de uma pequena caixa e colocá-la no meio de uma sala reservada, liberando-a para visitação pública.

Antes as paredes da casa dividiam o pequeno espaço doméstico do universo público, agora até mesmo as noções de pequeno e grande foram perturbadas. Como compreender um espaço pequeno que pode abranger um espaço infinito? Como limitar o espaço íntimo da casa, se dentro dela permanece uma janela aberta ininterruptamente para o mundo lá fora? Como entender a noção de casa enquanto espaço reservado, fora da vista de pessoas estranhas, se os meios de comunicação colocam o espaço privado de uma casa diante dos olhares de milhões de telespectadores (ou internautas), expondo-o ao domínio público? Habermas (1984, p.186) parecia prever esse emaranhado de espaço público e privado: "na mesma proporção em que a vida privada se torna pública, a esfera pública passa a assumir ela mesma, formas de intimidade”.

\section{Considerações finais}

O avanço vertigionoso das tecnologias de comunicação, a presença avassaladora da civilização da imagem, assim como mudanças intrigantes do panorama social e cultural significam não apenas alterações profundas na esfera da realidade, mas vem provocando igualmente uma revolução na nossa maneira de pensar e de desenvolver esquemas interpretativos nos domínios dos espaços públicos e privados, e particularmente nas configurações dos espaços comunicativos e de sociabilidade no interior da casa.

Até então, em grande parte das análises, a produção da comunicação vinha sendo vista como reflexo de determinações sociais mais profundas (os meios obedeceriam a uma lógica externa, advinda das esferas de poder da sociedade). Tratando especificamente do entrelaçamento comunicação e relações sociais, tais análises veem à comunicação como instância mediadora dessas relações - os meios seriam os instrumentalizadores de relações pré - definidas.

Contrariando essa posição, este artigo orienta-se para outra perspectiva de análise da comunicação e da contemporaneidade ao indicar que as novas tecnologias da comunicação alteram as relações dos espaços públicos e privados e, impacta substantivamente as formas de socialização no espaço da casa. A concepção de um novo cenário e o reordenamento dos espaços - a nova maneira de estar no espaço social via meios tecnológicos veio implodir o panorama da vida social. As diferentes relações estruturadoras da vida social tomam um novo formato na era 
das comunicações e das imagens reestruturando a natureza do espaço doméstico. Desta forma os meios de comunicação inauguram novas formas de socialibilidades no interior da casa.

Assim, orienta-se o trabalho a demonstrar que os estudos da comunicação nas sociedades contemporâneas devem envolver o estudo das relações comunicativas inscritas no terreno da experiência. No panorama contemporâneo, marcado pela exacerbação do espaço midiático, novas experiências se realizam no interior da casa, que se converte em espaço de realização da vida social com criação de laços que acontecem via computador, demarcando o sentido das interações comunicativas estabelecidas que não se confina na materialidade da mensagem, mas se completa e transborda para a ambiência onde os interlocutores estão imersos. Um sentido se constrói numa relação comunicativa: o sentido de um tempo, de um lugar e de um espaço.

O Estudo da comunicação e das novas formas de sociabilidades é também uma atividade de resgaste desta ambiência de sentido - a casa. Em lugar de isolar o espaço doméstico e privado, problematiza-se a sua inserção num terreno mais amplo, para compreender como ele realiza, compõe e pontua nossa existência cotidiana no que ela tem de banal, vivida e costumeira.

\section{REFERÊNCIAS:}

ARENDT, Hannah. A condição humana. Rio de Janeiro: Forense Universitária, 1993.

BACHELARD, Gaston. La poétique de l'espace. Paris : Presses Universitaires de France, 1970.

BRANDAO, Ludmila de Lima. A casa subjetiva: matérias, afectos e espaços domésticos. São Paulo: Perspectiva, 2002.

CAVALCANTI, Lauro; GUIMARAENS, Dinah. Morar - a casa brasileira. Rio de Janeiro: Avenir Editora, 1984.

CERTEAU, Michel de. A Invenção do Cotidiano: 1. artes de fazer. Petrópolis: Editora Vozes, 1990.

DAMATTA, Roberto. A casa e a rua - Espaço, cidadania, mulher e morte no Brasil. São Paulo: Editora Brasiliense, 1994.

FERREIRA, Angela; MARQUES, Sônia. "Privado e Público: Inovação Espacial ou Social”. In: Scripta Nova - Revista Electrônica de Geografia y Ciências Sociales. Disponível em: http://www.ub.es/geocrit/sn-69-20.htm. Acesso em: 10/05/10.

GIDDENS, Anthony. As conseqüências da modernidade. São Paulo: Editora UNESP, 1991. 
HABERMAS, Jürgen. Mudança estrutural da esfera pública. Rio de Janeiro: Tempo Brasileiro, 1984.

MONTORO, Tania. "Velhices e Envelhecimentos: dispersas memórias na cinematografia mundial". In: Maria Luisa Mendonça (Org.) Mídia e Diversidade Cultural: Experiências e Reflexões. PPGCOM- UFG. Editora Casa das Musas: Brasília, 2009. p.191-207.

MORAES, Denise. "O Sublime no cotidiano: análise do filme As Coisas Simples da Vida”. In: Tânia Montoro (Org.). De olho na imagem: cinema e televisão. Brasília: Editora Abaré, 2006, p.35-46.

NOVAIS, Fernando A. et al. História da vida privada no Brasil. São Paulo: Companhia das Letras, 1997.

PROST, Antoine; VICENT, Gérard (Org.). História da vida privada: 5. da primeira guerra a nossos dias. Tradução: Denise Bottman. São Paulo: Companhia das Letras, 2009.

SANTOS, Boaventura de Sousa. Pela mão de Alice: o social e o político na pós-modernidade. São Paulo: Cortez, 2000.

SENNETT, Richard. O Declínio do homem público. São Paulo: Companhia das Letras, 1988.

Original recebido em: 06/07/2011

Aceito para publicação em: 12/09/11

Resumo dos autores:

${ }^{1}$ Tania Montoro é professora e pesquisadora da Faculdade de Comunicação da Universidade de Brasília (UNB). Doutora em Comunicação Audiovisual pela Universidade Autônoma de Barcelona com pós-doutorado em Cinema pela Universidade Federal do Rio de Janeiro (UFRJ).

http://buscatextual.cnpq.br/buscatextual/visualizacv.do?id=K4793414E0

${ }^{2}$ Denise Cavalcante é professora da Faculdade de Comunicação da Universidade de Brasília (UNB), cineasta, mestre em Cinema pela Universidade de Brasília (UNB) e doutoranda do programa de pós-graduação em Comunicação da Universidade de Brasília (UnB), linha de pesquisa: Imagem e Som.

http://buscatextual.cnpq.br/buscatextual/visualizacv.do?id=K4735724A6 